\title{
Stictic Acid Derivatives from the Lichen Usnea articulata and their Antioxidant Activities
}

Françoise Lohézic - Le Dévéhat ${ }^{* \dagger}$, Sophie Tomasi ${ }^{\dagger}$, John A. Elix ${ }^{\ddagger}$, Aurélie Bernard ${ }^{\dagger}$, Isabelle Rouaud ${ }^{\dagger}$, Philippe Uriac ${ }^{\dagger}$, and Joël Boustie ${ }^{\dagger}$

Institut de Chimie de Rennes, EA 4090 "Substances Lichéniques et Photoprotection", Faculté de Pharmacie, 2 Avenue du Professeur Léon Bernard, 35043 Rennes Cedex, France, Department of Chemistry, The Faculties, Australian National University, Canberra, ACT 0200, Australia

\section{Supporting Information}

\section{Contents}

S1. ${ }^{1} \mathrm{H}$ NMR spectrum of compound 1

S2. HMQC spectra of compound 1

S3a-d. HMBC spectra of compound 1

S4. ${ }^{1} \mathrm{H}$ NMR spectrum of compound 2

S5. ${ }^{13} \mathrm{C}$ NMR spectrum of compound 2

\footnotetext{
* To whom correspondence should be addressed. Phone: + 33 (0) 2232348 16. Fax: + 33 (0) 22323 47 04. E-mail: francoise.le-devehat@univ-rennes1.fr

$\dagger$ Institut de Chimie de Rennes, Rennes Cedex, France.

$\$$ Department of Chemistry, Canberra, ACT 0200, Australia.
} 


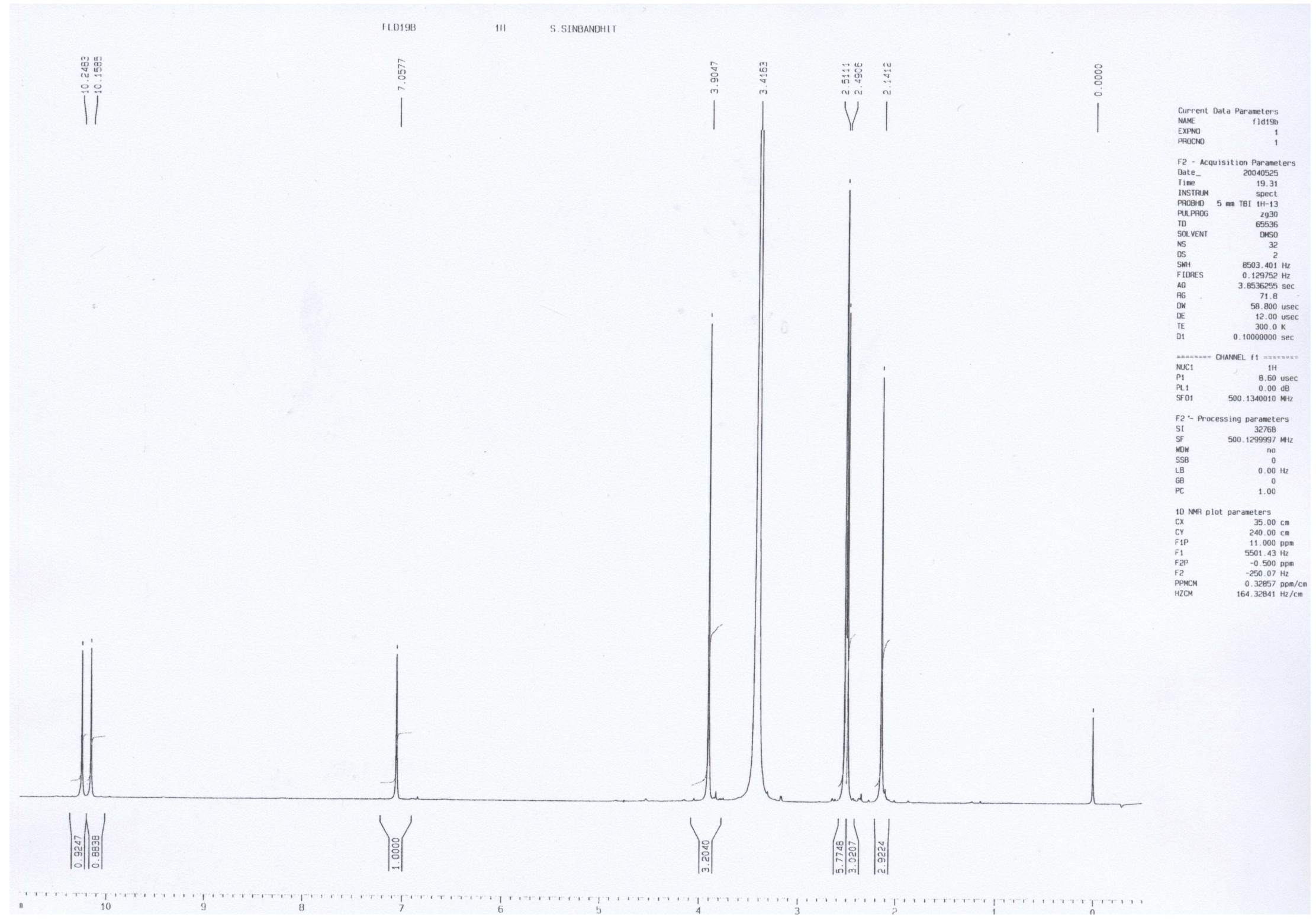




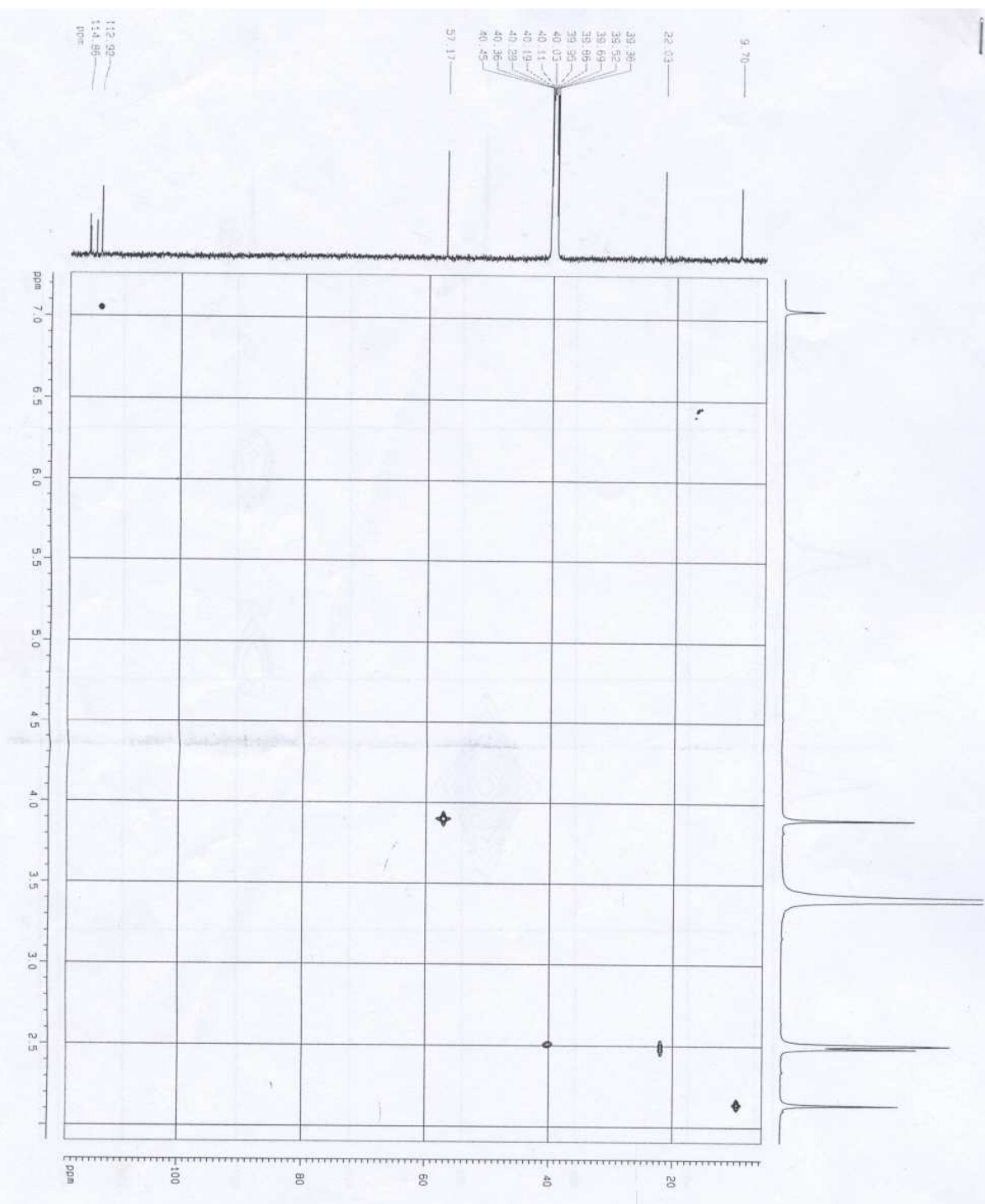

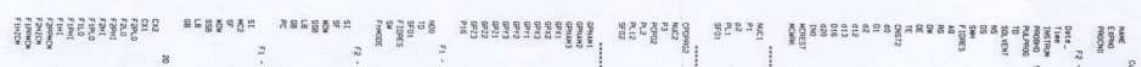

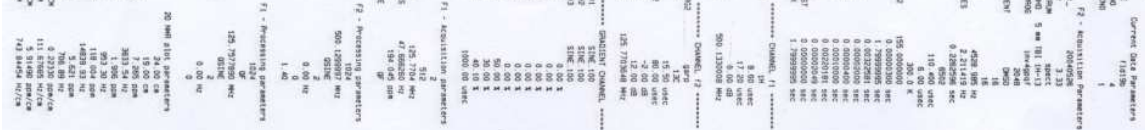

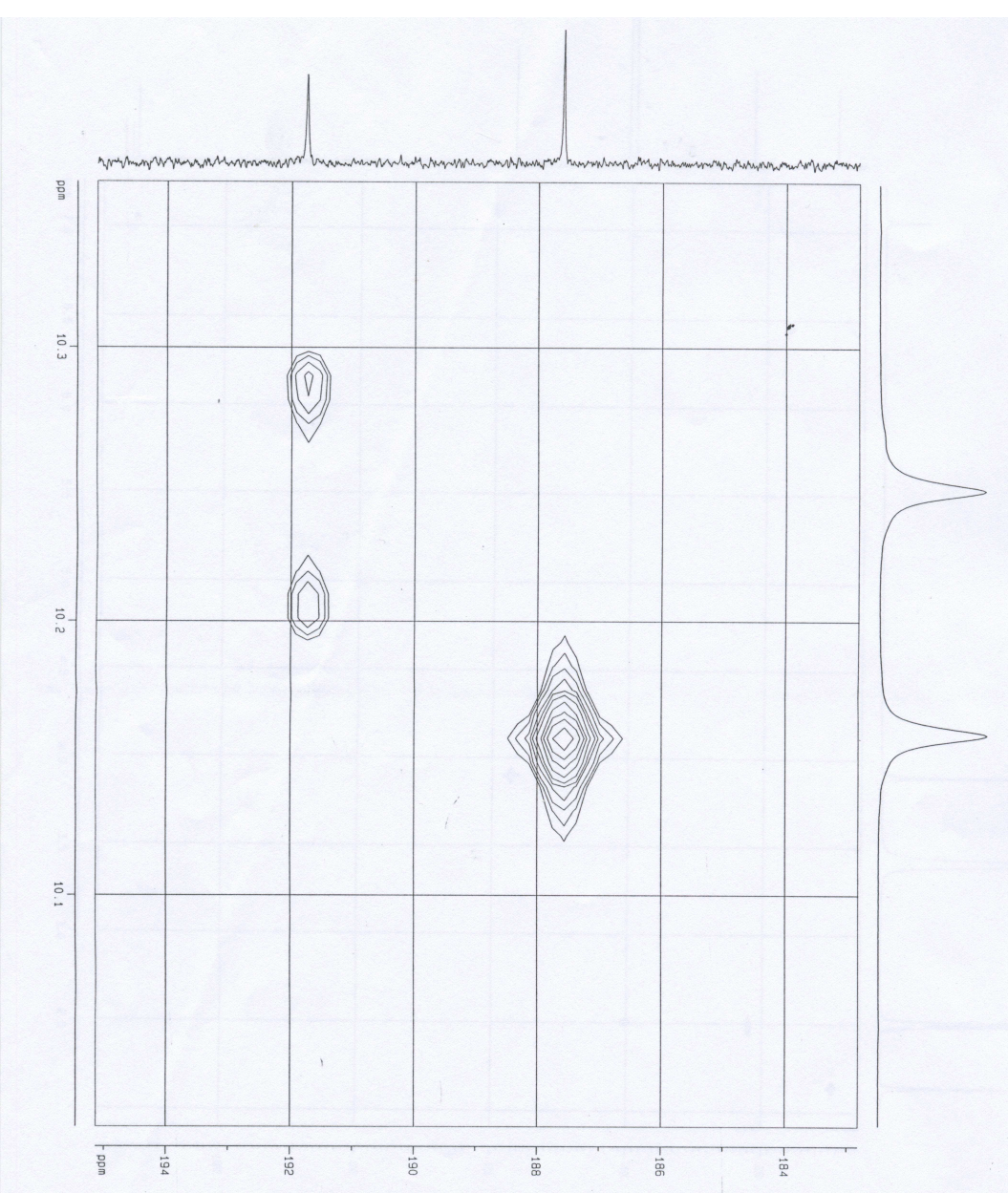

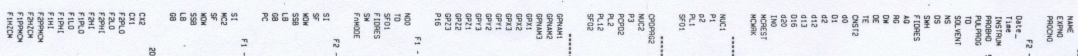

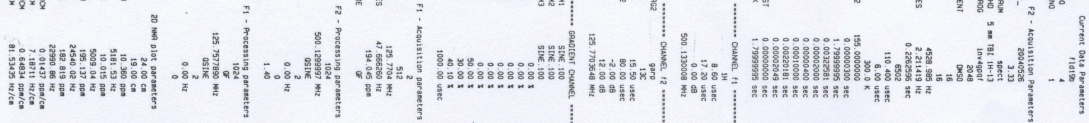




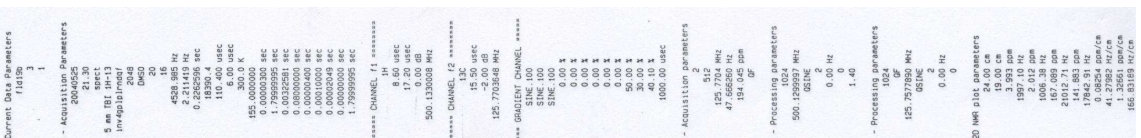

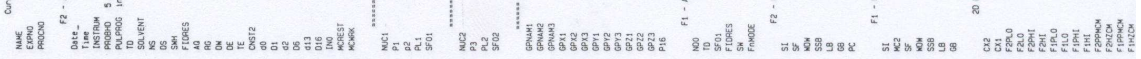

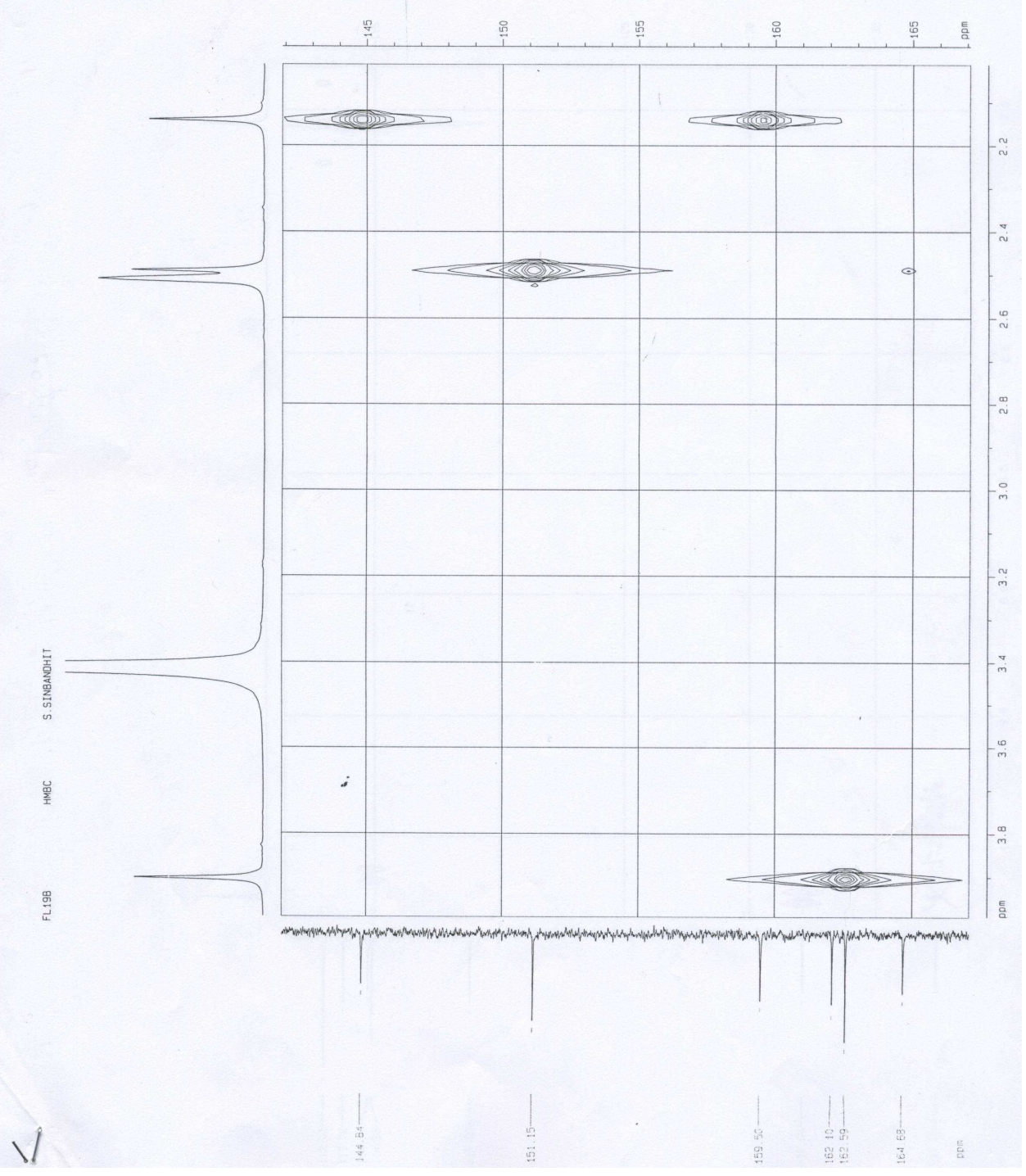

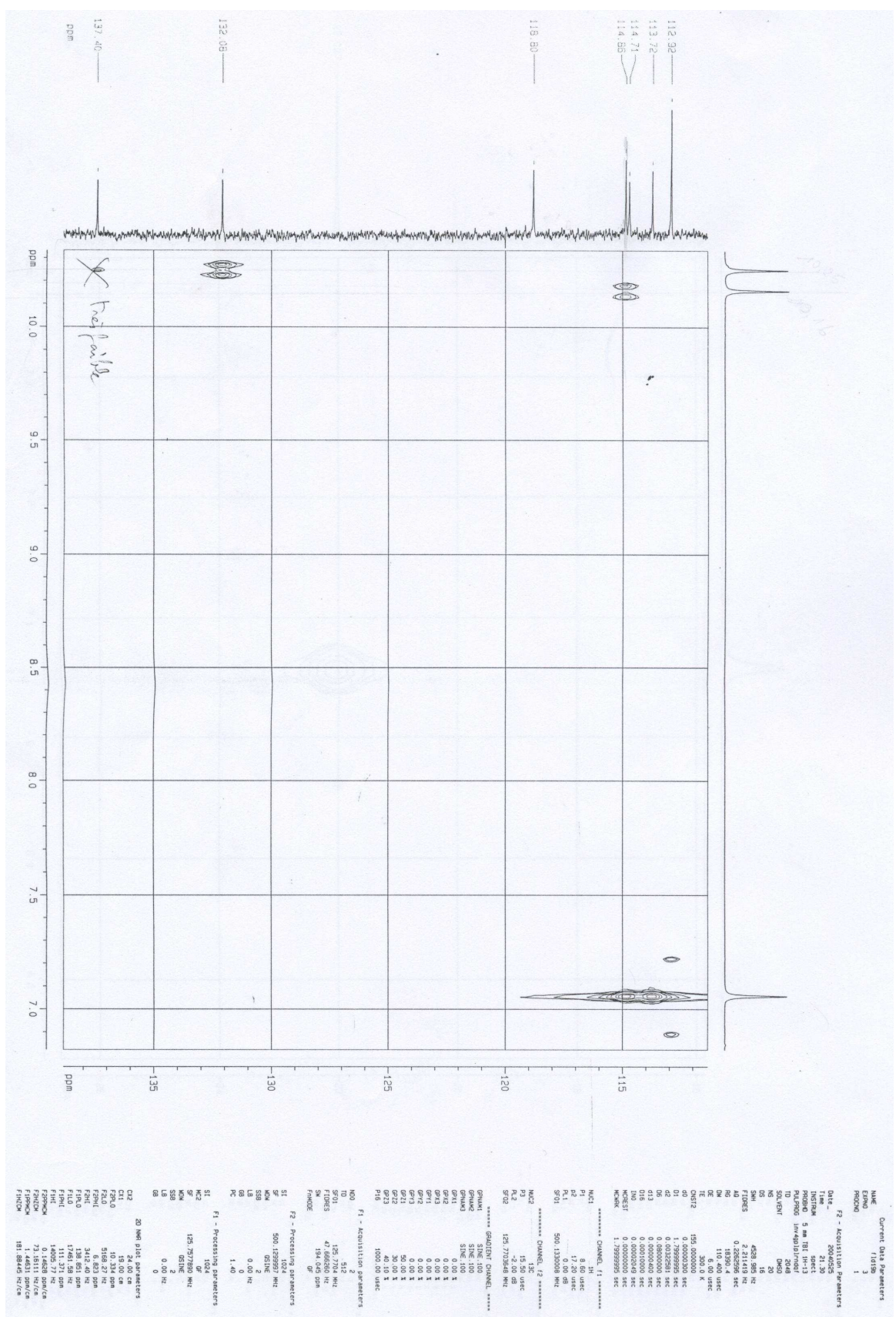




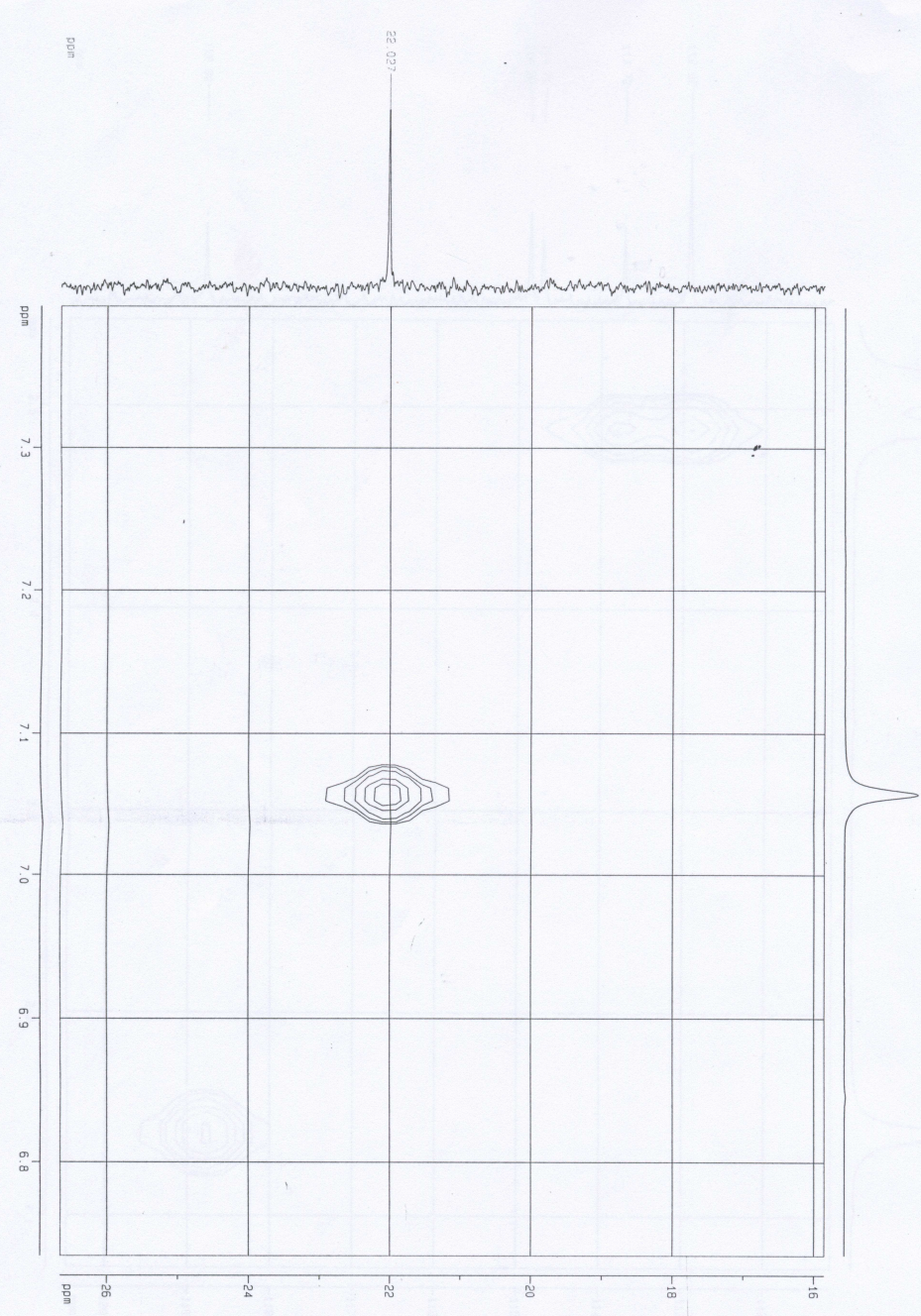

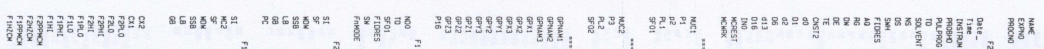

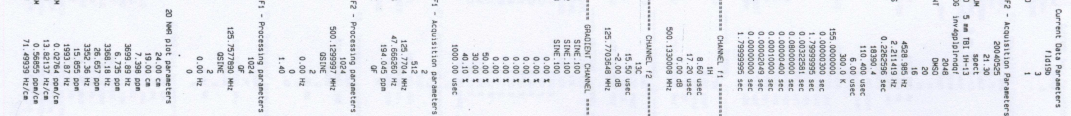
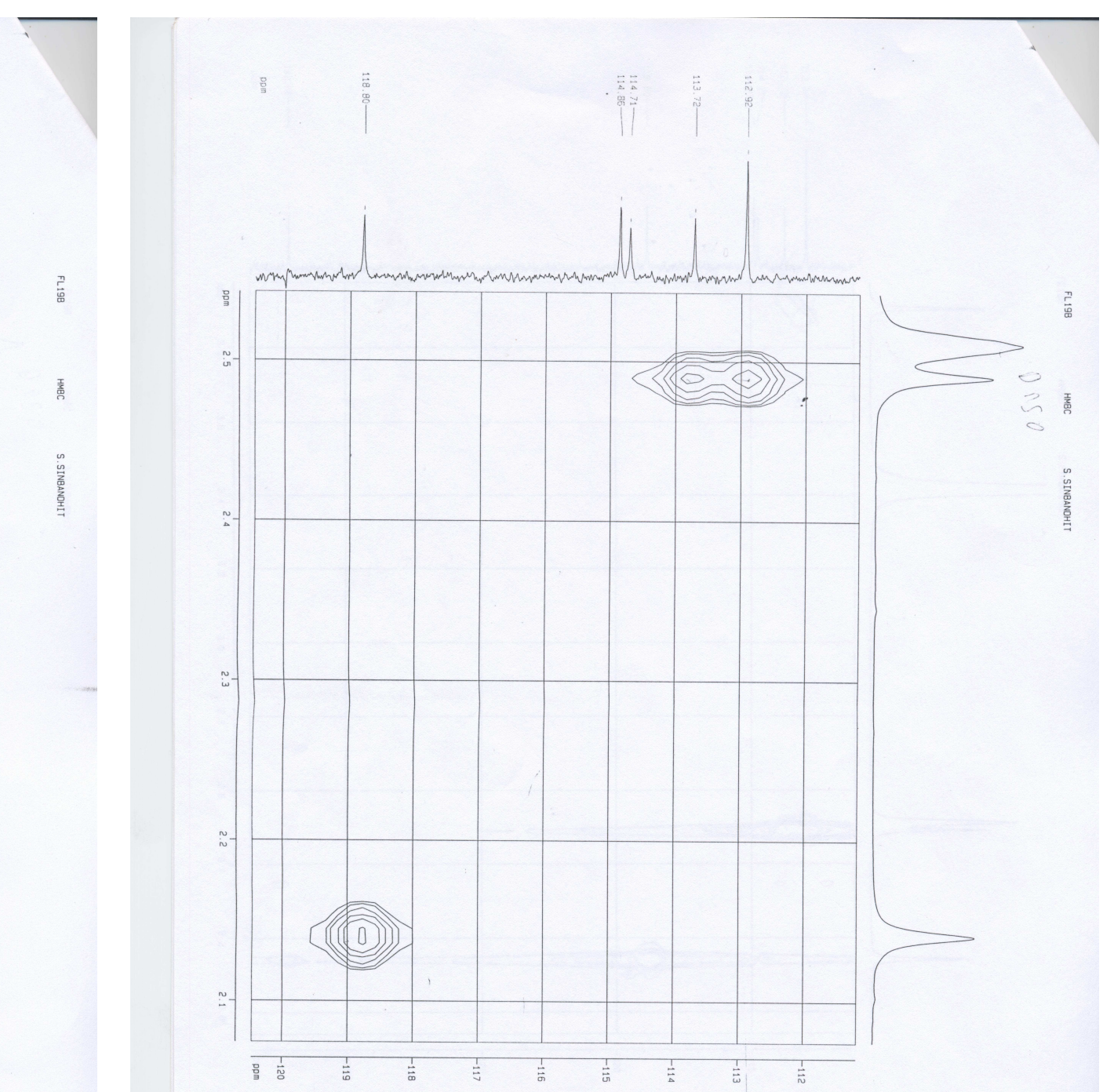

WVY

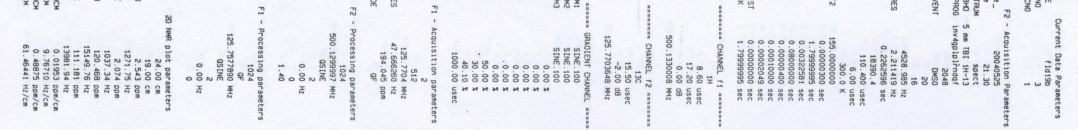


S3c. HMBC $\left(500 \mathrm{MHz}\right.$, DMSO- $\left.\mathrm{d}_{6}\right)$ of the new compound 1

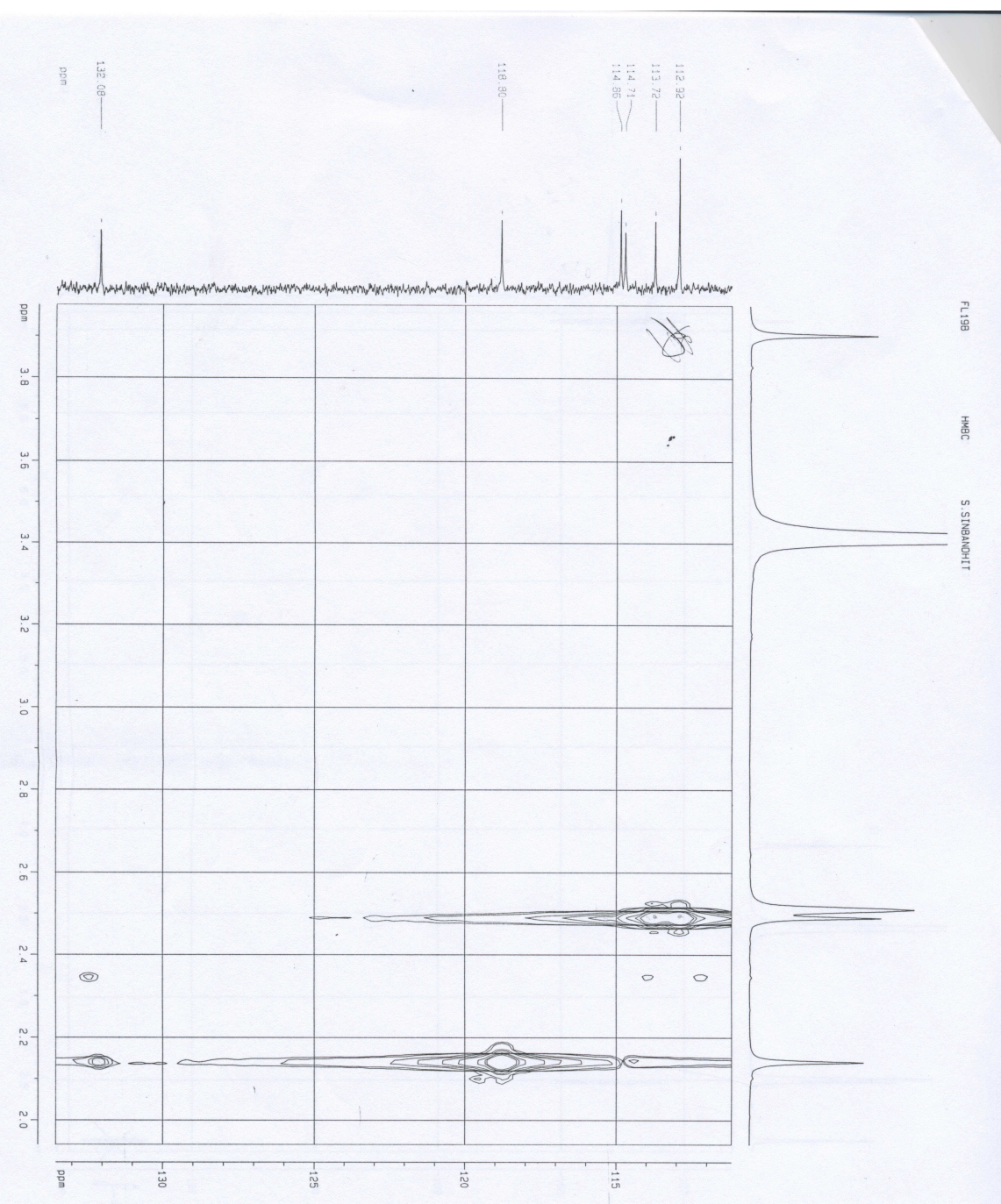

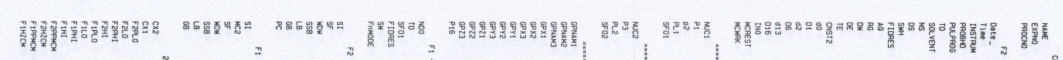

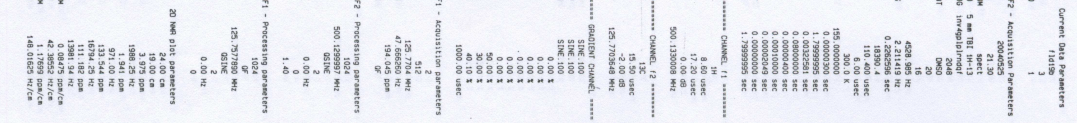

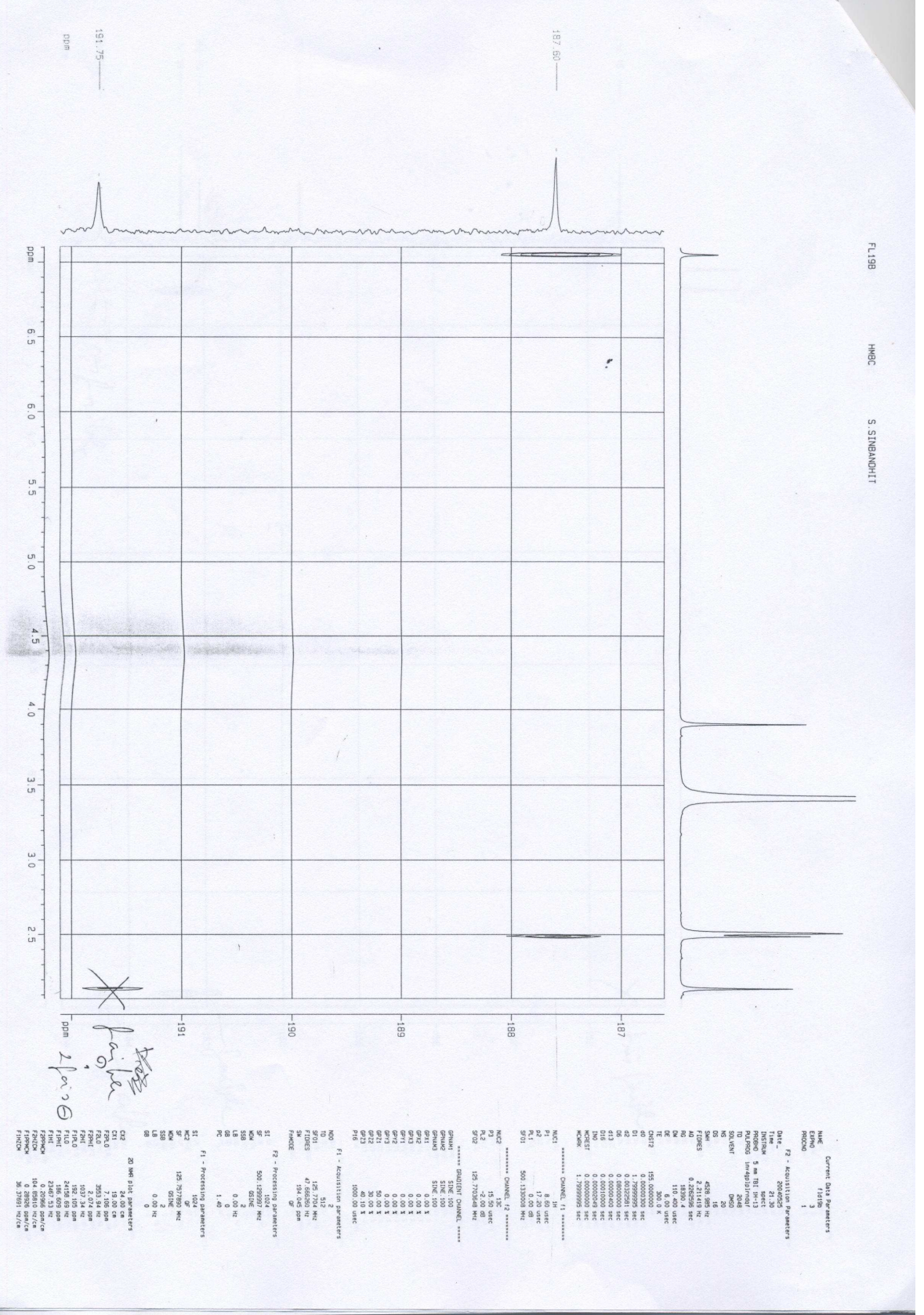




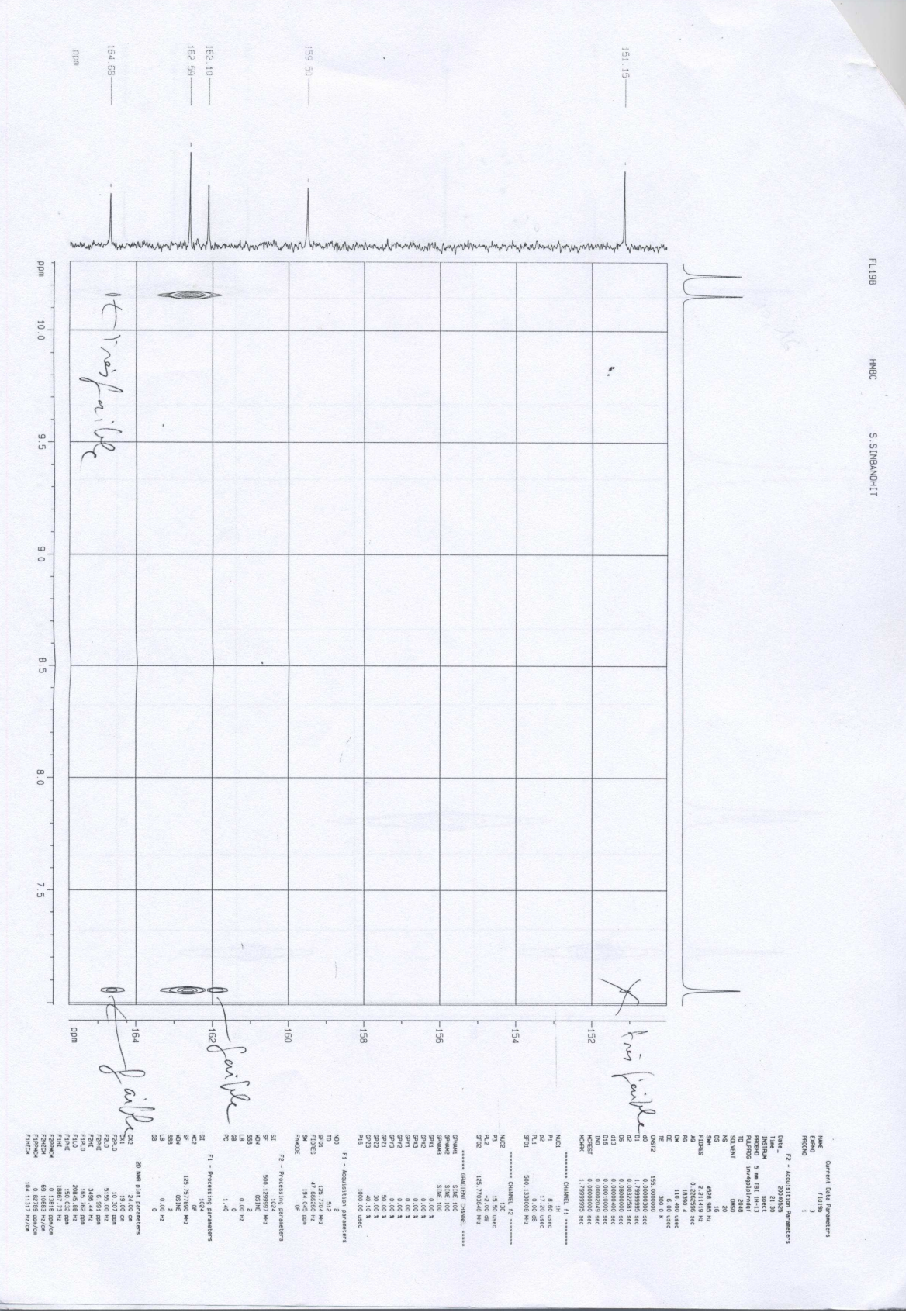


S4. ${ }^{1} \mathrm{H}$ NMR (500 MHz, DMSO-d $\mathrm{d}_{6}$ ) of the new compound 2

\{1d30 1h sp. normal mir

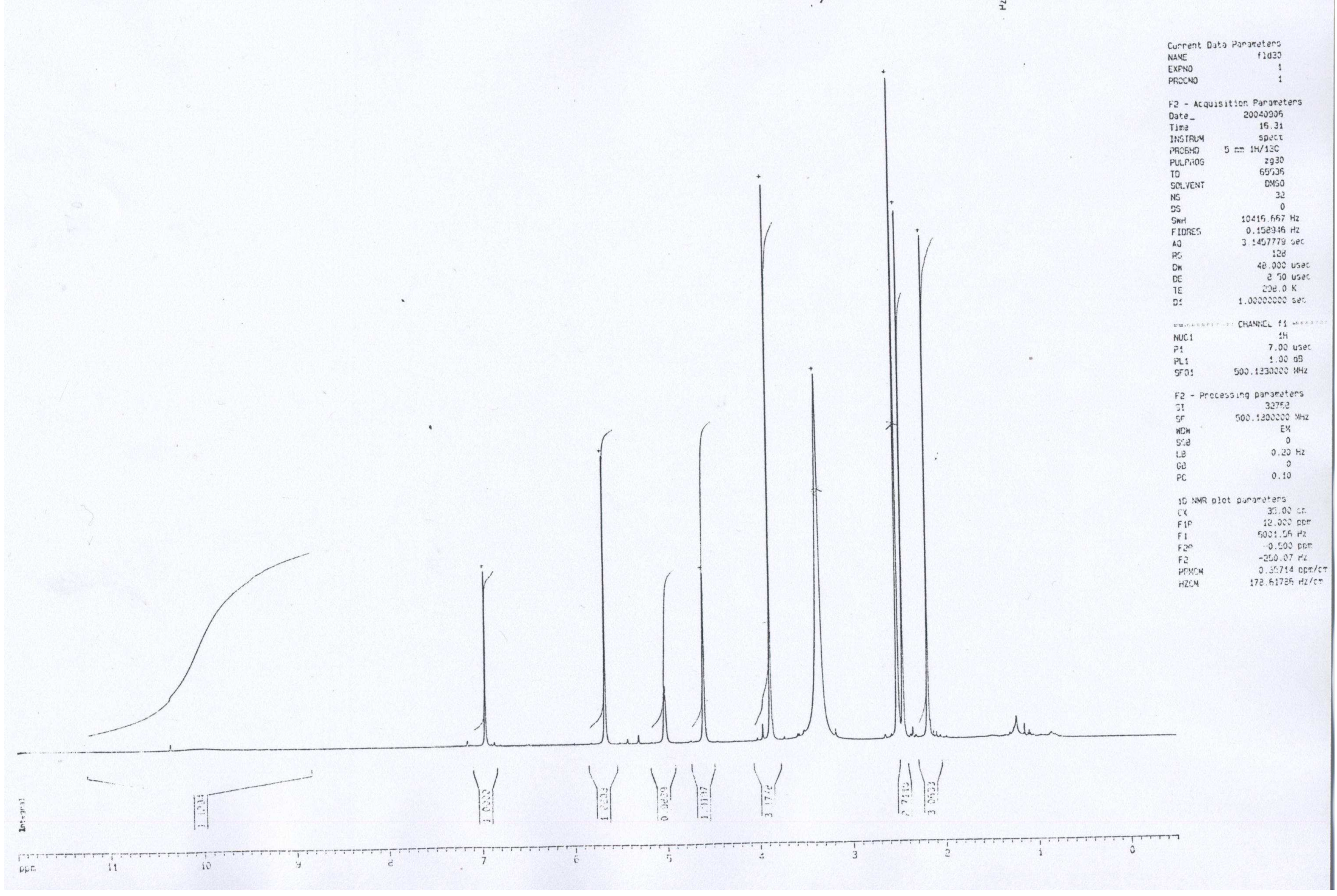


S5. ${ }^{13} \mathrm{C}$ NMR (125 MHz, DMSO- $\left.\mathrm{d}_{6}\right)$ of the new compound 2

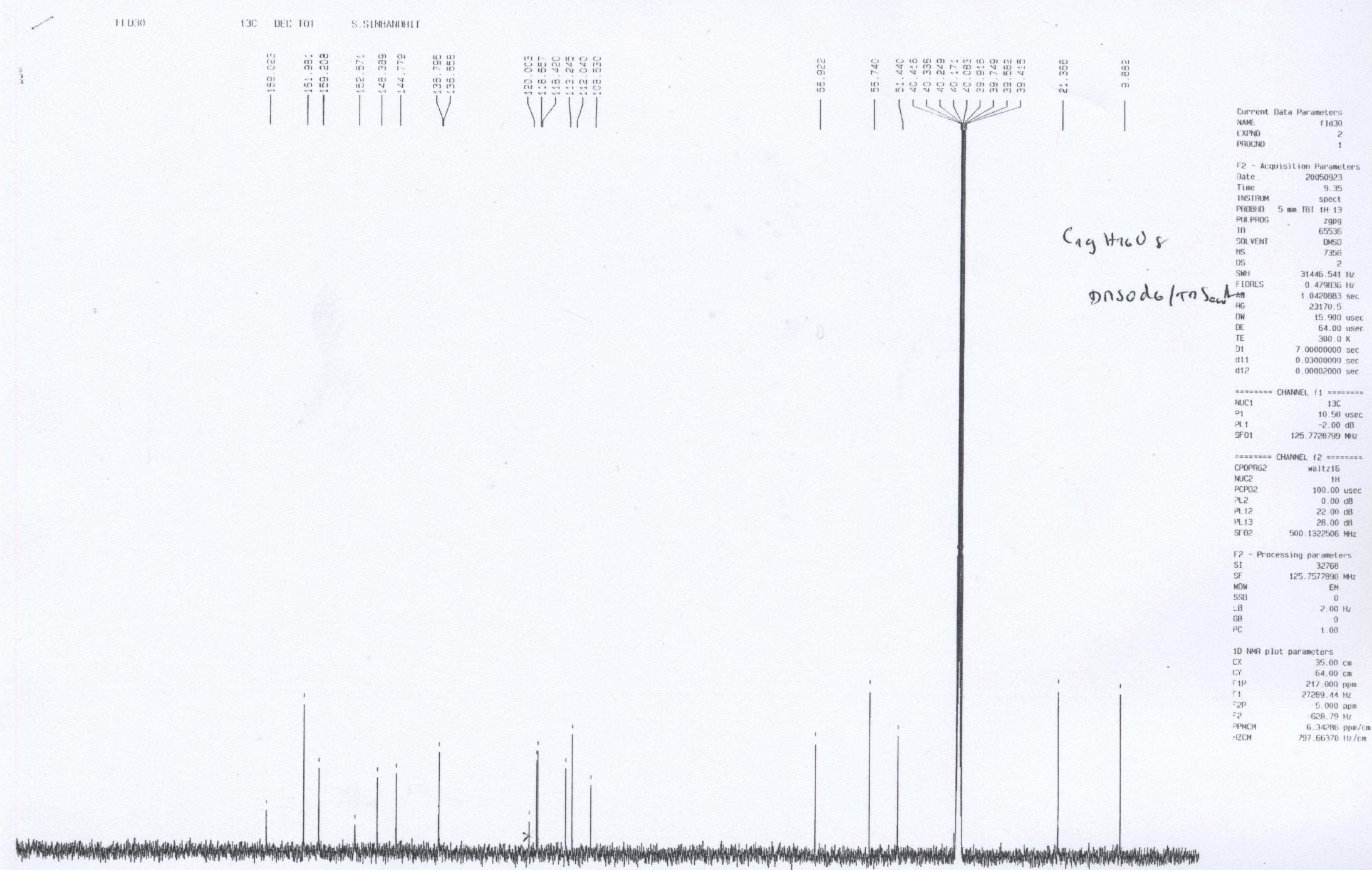

